\title{
The Role of High-Density Lipoprotein in COVID-19
}

\author{
Guyi Wang ${ }^{1}$, Jiayi Deng ${ }^{1}$, Jinxiu $L i^{1}$, Chenfang $W u^{1}$, Haiyun Dong ${ }^{1}$, Shangjie $W u^{2}$ and \\ Yanjun Zhong ${ }^{\text {* }}$
}

${ }^{1}$ Department of Critical Care Medicine, The Second Xiangya Hospital, Central South University, Changsha, China, ${ }^{2}$ Department of Respiratory, The Second Xiangya Hospital, Central South University, Changsha, China

The current Coronavirus disease 2019 (COVID-19) pandemic has become a global challenge. Managing a large number of acutely ill patients in a short time, whilst reducing the fatality rate and dealing with complications, brings unique difficulties. The most striking pathophysiological features of patients with severe COVID-19 are dysregulated immune responses and abnormal coagulation function, which can result in multiple-organ failure and death. Normally metabolized high-density lipoprotein (HDL) performs several functions, including reverse cholesterol transport, direct binding to lipopolysaccharide (LPS) to neutralize LPS activity, regulation of inflammatory response, anti-thrombotic effects, antioxidant, and anti-apoptotic properties. Clinical

\section{OPEN ACCESS}

Edited by:

Brijesh Kumar Singh, Duke-NUS Medical School, Singapore

Reviewed by: Abhigyan Satyam, Harvard Medical School,

United States

Kristen M. Tecson, Baylor Scott \& White Research Institute (BSWRI), United States

*Correspondence: Yanjun Zhong zhongyanjun@csu.edu.cn

Specialty section: This article was submitted to Experimental Pharmacology and Drug Discovery, a section of the journal Frontiers in Pharmacology

Received: 04 June 2021 Accepted: 06 July 2021 Published: 16 July 2021

Citation:

Wang G, Deng J, Li J, Wu C, Dong H, Wu S and Zhong Y (2021) The Role of High-Density Lipoprotein in COVID-19.

Front. Pharmacol. 12:720283. doi: 10.3389/fphar.2021.720283 data shows that significantly decreased HDL levels in patients with COVID-19 are correlated with both disease severity and mortality. However, the role of HDL in COVID-19 and its specific mechanism remain unclear. In this analysis, we review current evidence mainly in the following areas: firstly, the pathophysiological characteristics of COVID-19, secondly, the pleiotropic properties of HDL, thirdly, the changes and clinical significance of HDL in COVID-19, and fourthly the prospect of HDLtargeting therapy in COVID-19 to clarify the role of HDL in the pathogenesis of COVID-19 and discuss the potential of HDL therapy in COVID-19.

Keywords: COVID-19, SARS-CoV-2, lipoproteins, HDL, angiotensin-converting enzyme 2

\section{INTRODUCTION}

Coronavirus disease 2019 (COVID-19), caused by severe acute respiratory syndrome coronavirus 2 (SARS-CoV-2), outbroke in Wuhan in late 2019 (Guan W.-J. et al., 2020; Wang et al., 2020a; Huang C. et al., 2020; Hui et al., 2020; Lu et al., 2020). It has since spread worldwide (Albarello et al., 2020; Giunta et al., 2020; Young et al., 2020). By June 30, 2021, more than 180 million people have been infected with SARS-CoV-2, and nearly four million have died globally (WHO, 2021a). The COVID19 pandemic has become a significant burden on global healthcare systems. Patients with COVID-19 with underlying metabolic dysfunction, such as type 2 diabetes and non-alcoholic fatty liver disease, have a higher risk of poor outcomes (Guan W.-j. et al., 2020; Mahamid et al., 2020; Ji et al., 2021). A decline in total cholesterol, high-density lipoprotein (HDL), and low-density lipoprotein (LDL) levels in patients with COVID-19 has been observed in several studies, including our previous research (Wei et al., 2020a; Wang et al., 2020b). Our data also shows that among the several lipids named above, only HDL was associated with the severity of COVID-19 (Wang G. et al., 2020). In this review, we aim to analyze the available evidence about how HDL dysfunction is associated with infection, including a focus on COVID-19. 


\section{SARS-COV-2}

SARS-CoV-2 is a positive-sense, single-stranded RNA virus, surrounded by an envelope (Han et al., 2020; Kočar et al., 2021). SARS-CoV-2 is reported to share $79.6 \%$ homology with SARS-CoV (Zhou F. et al., 2020). The highly pathogenic CoVs, including Middle East Respiratory Syndrome (MERS) CoV, SARS-CoV-1, and SARS-CoV-2, mainly invade the lower respiratory tract through the upper respiratory tract and result in fatal pneumonia (Han et al., 2020).

SARS-CoV-2 entry into susceptible host tissue cells depends on the host cell angiotensin-converting-enzyme 2 (ACE2) receptor via the spike (S) protein, followed by $S$ protein cleaving and membrane fusion (Chambers et al., 2020). ACE2 is widely expressed in human tissues, including in lung alveolar epithelial cells, small intestinal epithelial cells, vascular endothelial cells and smooth muscle cells within the lung, kidney, intestines, and other organs (Kočar et al., 2021).

\section{PATHOPHYSIOLOGICAL CHARACTERISTICS OF COVID-19}

COVID-19 causes significant infection-related morbidity and mortality. There have been about 33 million positive cases and nearly 600 thousand deaths in America (WHO, 2021b), while in China, there have been about 118 thousand positive cases and about five thousand deaths (WHO, 2021c). A recent metaanalysis of 212 studies from 11 countries/regions involving 281,461 individuals showed about $22.9 \%$ of patients with COVID-19 had severe disease and 5.6\% patients die ( $\mathrm{Li}$ J. et al., 2021). The most striking pathophysiological feature of patients with severe COVID-19 is a dysregulated immune response, characterized by lymphopenia and a cytokine storm, which results in acute respiratory distress syndrome, hepatic dysfunction, multiple-organ failure, and ultimately death. Abnormal coagulation function is also a prominent feature in severe COVID-19 cases (Beltrán-García et al., 2020; José et al., 2020; Song et al., 2020; Zafer et al., 2021).

\section{Dysregulated Immune Responses}

SARS-CoV-2 may activate both innate and adaptive immune responses in patients, including lymphopenia, cytokine release syndrome, and abnormal activation of macrophages and their complement system (Jamal et al., 2021). Lymphopenia, involving a drastic reduction in T-cells and B cells (Qin et al., 2020a; Tan et al., 2020; Xu et al., 2020), is a common feature in patients with severe COVID-19. This is possibly triggered by SARS-CoV-2induced activation of apoptosis in lymphocytes (Xiong et al., 2020).

Patients with COVID-19 have also shown monocyte/ macrophages morphological and physiological changes. These monocytes were characterized by mixed M1/M2 polarization, relatively elevated $\mathrm{CD}^{+} 0^{+}$and $\mathrm{CD}_{20}{ }^{+}$expression, and higher secretion of interleukin (IL)-6, IL-10, and tumor necrosis factor (TNF)- $\alpha$ (Zhang D. et al., 2021). Macrophages infiltrated into the lungs of patients with COVID-19 were mostly type 1 (Yao et al.,
2020). Monocytes obtained from patients with COVID-19 were shown to express ACE2 receptors, suggesting SARS-CoV-2 may directly infect and affect monocytes and macrophages in COVID19 (Zhang Y. et al., 2021). Additionally, cytokine storms were common in patients with severe COVID-19. Patients exhibited increased cytokine secretion, particularly IL-2, IL-4, IL-6, IL-10, TNF- $\alpha$, and interferon (IFN)- $\gamma$ (Qin et al., 2020b). The possible causes of this cytokine release syndrome could be a dysregulated immune response incapable of controlling the production of excessive amounts of cytokines and chemokine.

The complement system was also considered to play a pivotal role in COVID-19. A recent study showed that complement components of the classical (C1q, C4d) and alternative (Factor $\mathrm{H}$, C3d) pathways were deposited in the lungs of people with COVID-19, indicating the activation of complement system in COVID-19 (Satyam et al., 2021). Early clinical reports indicates that C3 inhibition therapy holds potential anti-inflammatory properties in COVID-19 (Mastaglio et al., 2020; Satyam and Tsokos, 2020) and anti-complement C5 therapy in patients with severe COVID-19 lead to a drop in inflammatory markers and a successful recovery (Diurno et al., 2020; Satyam and Tsokos, 2020).

\section{Abnormal Coagulation}

Abnormal coagulation function is also a prominent feature in severe COVID-19 cases. Severe COVID-19 was associated with widespread activation of the coagulation system, corroborated by elevated activated partial thromboplastin time (APTT) and prothrombin time (PT) along with markedly elevated D-dimer levels (Tang et al., 2020; Zhou P. et al., 2020). Severe endothelial injury and widespread thrombosis with microangiopathy are evident in lungs from patients with COVID-19 (Ackermann et al., 2020). Possible causes include a direct attack by the virus on the endothelial cells via ACE-2 receptors (Ackermann et al., 2020), and cytokine storms such as TNF and IL-6, which are potent activators of the tissue factor (TF)-dependent coagulation cascade (Tijburg et al., 1991; Kerr et al., 2001).

\section{COMPOSITION, METABOLISM AND FUNCTION OF HDL}

HDL is a type of lipoprotein with an extremely heterogeneous composition, density, and particle size, containing cholesterol, phospholipids, triglycerides, and apolipoproteins. It was first isolated from blood in the 1960s by ultracentrifugation. Among all types of human plasma lipoproteins, HDL, mainly synthesized in the liver and small intestine, has the highest density and smallest volume in the circulatory system. Apolipoprotein A-I (ApoA-I) is the main structural protein component of $\mathrm{HDL}$, and other protein components such as serum amyloid A (SAA), lecithin cholesterol acyltransferase (LCAT), paraoxonase-1 (PON-1) and cholesterol ester transfer protein (CETP) also participate in the metabolic process of HDL (Gordon et al., 1989; Ginsberg, 1998; Tosheska Trajkovska and Topuzovska, 2017). 


\section{Reverse Cholesterol Transport}

Normally metabolized HDL has various functions. The most important and well characterized function is the regulation of reverse cholesterol transport. During the formation and maturation of HDL, its main functional protein, ApoA-I, continuously binds to free cholesterol in tissue cells, and is then transported to the liver. Thus, cholesterol is excreted from the body's tissue cells through a series of transport and transformation processes, which reduces the cholesterol level in the body and delays the occurrence and progression of coronary heart disease (Gordon et al., 1989; Rader, 2003; Tosheska Trajkovska and Topuzovska, 2017).

\section{Direct Binding to Lipopolysaccharide and Neutralizing LPS Activity}

LPS is the chief component of the outer membrane of Gramnegative bacteria. Numerous studies have found that HDL prevents systemic endotoxemia by binding and neutralizing LPS (Parker et al., 1995), which is considered to be the main mechanism of HDL's antimicrobial effect (Ulevitch et al., 1979; Freudenberg et al., 1980). Early studies have shown that HDL can prevent the activation of peripheral blood monocytes and macrophages by LPS, and reduce the synthesis and secretion of inflammatory cytokines such as TNF- $\alpha$ and IL-1 $\beta$ (Levine et al., 1993). In vivo studies have shown that the initiation of intravenous infusion of recombinant HDL prior to induction of endotoxemia in healthy volunteers significantly reduced TNF, IL-6, and IL-8 levels, as well as reducing endotoxin-induced clinical symptoms and leukocyte activation (Pajkrt et al., 1996). A recent study showed that, compared with normal mice, ApoA-I (the main component of HDL) knockout mice showed increased production of inflammatory cytokines, decreased ability to neutralize and clear LPS, and reduced survival (Guo et al., 2013). In addition to binding and neutralizing LPS, HDL also promotes LPS clearance, mainly binding with SR-B1 and mediating LPS intake. It has been reported that in LPS-induced endotoxemia and cecal ligation and puncture (CLP) sepsis models in vitro, SR-B1 gene deletion mice showed decreased endotoxin clearance (Cai et al., 2008; Guo et al., 2009).

\section{Regulation of Inflammatory Response}

HDL may also be a key regulator of inflammatory response. Invitro cell experiments show that HDL inhibits a subset of LPSstimulated macrophage genes that regulate the type I interferon response via microarray analysis (Suzuki et al., 2010). HDL also down-regulates the expression of Toll-like receptor (TLR)induced pro-inflammatory cytokines through the transcriptional regulator activating transcription factor 3 (ATF3) (De Nardo et al., 2014). Transgenic mice with 2-foldelevated plasma HDL levels had lower plasma cytokine levels, and improved survival rates in an endotoxemia mouse model (Levine et al., 1993).

\section{Anti-Thrombotic Effects}

HDL can act as a regulator of platelet and coagulation responses in a variety of ways. Numerous epidemiological studies have established an inverse correlation between HDL levels and the risk of thrombosis (Sharrett et al., 2001; Deguchi et al., 2005; Lüscher et al., 2014), and many studies have explored the mechanisms involved. HDL stimulates $\mathrm{NO}$ and prostacyclin production in endothelial cells which are both inhibitors of platelet activation (Van Sickle et al., 1986; Yuhanna et al., 2001; Calabresi et al., 2003). Endothelial cells express TF after thrombin-induction in acute coronary syndromes, and HDL presents an atheroprotective effect by inhibiting thrombininduced human endothelial TF expression (Viswambharan et al., 2004). HDL, mainly ApoA-I, also protects endothelial cells against oxidized LDL (oxLDL) and prevents its apoptosis (Suc et al., 1997). Additionally, purified HDL enhances inactivation of coagulation factor $\mathrm{Va}$ by activated protein $\mathrm{C}$ (APC) and protein S (Griffin et al., 1999). ApoA-I also neutralizes the procoagulant properties of anionic phospholipids, and incorporation of ApoA-I in anionic vesicles prevents the formation of the prothrombinase complex (Oslakovic et al., 2009; Oslakovic et al., 2010).

\section{Antioxidant and Anti-Apoptotic Properties}

HDL can prevent intracellular reactive oxygen species (ROS) production, triggered by oxLDL or $\mathrm{H}_{2} \mathrm{O}_{2}$, thereby inhibiting the subsequent proteasome activation, and NF-kappa $\mathrm{B}$ activation (Robbesyn et al., 2003). HDL exerts a protective effect against oxidative damage induced by copper ions (Ferretti et al., 2003). Additionally, PON-1 is an HDL-associated esterase, which protects lipoproteins against oxidation. It is demonstrated that PON-1-deficient mice were susceptible to oxidative stress and HDL isolated from these mice were unable to prevent LDL oxidation (Shih et al., 1998).

HDL was shown to have the capacity to inhibit apoptosis of endothelial cells induced by oxLDL (Suc et al., 1997). HDL also prevented caspase- 3 and caspase- 9 activation, as well as apoptotic alterations of the plasma membrane (Nofer et al., 2001). In addition, HDL reduced cardiomyocyte apoptosis in a mouse model of myocardial ischemia/reperfusion (Theilmeier et al., 2006).

\section{HDL CHANGES DURING HUMAN INFECTION}

\section{Changes in Levels or Functions of HDL}

Levels and functions of HDL changed significantly in patients infected with different pathogens. Multiple studies show HDL decreased in many infections, including sepsis, nosocomial infections, dengue, Helicobacter pylori infection, and HIV infection (Canturk et al., 2002; van Leeuwen et al., 2003; Chien et al., 2005; Rose et al., 2006; Jia et al., 2009; Aragonès et al., 2010; Baker et al., 2010; Zou et al., 2016; Cirstea et al., 2017; Tanaka et al., 2017; Barrientos-Arenas et al., 2018). The explanations includes decreased HDL synthesis, overconsumption of HDL particles, or HDL redistribution from intravascular to extravascular space (Pirillo et al., 2015; Tanaka et al., 2020a; Cao et al., 2020). Infection not only leads to a decrease in HDL levels, but also affects its function. HDL from $\mathrm{HIV}+$ individuals has reduced antioxidant function (Angelovich 
et al., 2017), modified HDL metabolism, and reduced functionality of reverse cholesterol transport (Rose et al., 2008). In mice models, HDL loses its anti-inflammatory properties after acute influenza infection (Van Lenten et al., 2001).

\section{Relationship Between HDL, Susceptibility of Infection and Outcome}

Low serum HDL levels seem to be associated with a higher risk of infectious diseases, including sepsis (Shor et al., 2008; Grion et al., 2010), nosocomial infection after surgery (Delgado-Rodriguez et al., 1997; Canturk et al., 2002), and in-hospital infection in patients with acute ischemic stroke (Rodríguez-Sanz et al., 2013). Furthermore, a prospective population-based cohort study involving more than 100,000 patients showed a U-shaped association of HDL with the risk of infectious disease, and that both high and low levels of HDL were related with a high risk of infection (Madsen et al., 2018). In addition, mortality rates, intensive care unit (ICU) stay, and length of hospital stay, all increased among septic patients with lower levels of HDL or ApoA-I (Chien et al., 2005; Montero-Chacón et al., 2020). Low HDL level at admission was also associated with severe sepsis (Grion et al., 2010). Lower HDL may herald a bad outcome, while higher levels of HDL seem to have a protective effect toward infection.

\section{Therapeutic Strategy Targeting HDL in Infection}

Due to the important role of HDL in infection, therapeutic strategy targeting $\mathrm{HDL}$ is considered as a possible new approach to the treatment of infection. Reconstituted HDL was shown to reduce inflammation and bacterial burden, attenuate organ injury and improve survival in experimental septic models (Levine et al., 1993; McDonald et al., 2003; Tanaka et al., 2020b; Tanaka et al., 2020c). Trypanosome lytic factor, as a minor subfraction of HDL, ameliorates Leishmania infection, possibly due to the ability to selectively damage pathogens in phagolysosomes (Samanovic et al., 2009). CETP is a key regulator of HDL levels. Its gain-of-function variant was significantly associated with an increased risk of mortality in sepsis (Trinder et al., 2019). CETP inhibitor Anacetrapib preserved levels of HDL and ApoA-I and increased the survival rate in CLP sepsis models (Trinder et al., 2021).

\section{ASSOCIATION BETWEEN HDL AND COVID-19}

\section{Alteration of HDL Level in Patients With COVID-19}

A large number of studies have shown a close correlation of HDL with COVID-19, which were summarized in Table 1. The serum HDL level in patients with COVID-19 was lower than that in healthy controls (Huang et al., 2021). A genome-wide association study (GWAS) summary analysis of 7362 COVID-19 participants from the United Kingdom Biobank, showed that individuals with a lower level of HDL were more vulnerable to SARS-CoV-2 infection (Zhang D. et al., 2021). A clinical observational study also found that lower HDL levels were related to a higher risk of SARS-CoV-2 infection (Aung et al., 2020), while higher HDL levels were associated with a lower risk of SARS-CoV-2 infection (Ho et al., 2020).

\section{Changes of HDL Function in Patients With COVID-19}

In addition to HDL levels, the composition and functions of HDL in COVID-19 were also changed. ApoA-I and PON-1 were less abundant in patients with COVID-19, whereas, using proteomic analyses, SAA and alpha-1 antitrypsin were found to be higher (Begue et al., 2021). HDL from patients with COVID-19 showed less protection in TNF- $\alpha$ treated endothelial cells (Begue et al., 2021). Generally, patients with diabetes and elderly patients showed a higher extent of glycation (Kawasaki et al., 2002; Park and Cho, 2011). Glycated HDL showed much lower antivirus activity against SARS-CoV-2 than that of native HDL, which may explain why older patients and patients with underlying conditions such as diabetes are more likely to develop severe illness and death in COVID-19 (Cho et al., 2021).

\section{Relationship of HDL With the Outcomes of Patients With COVID-19}

Additionally, HDL or ApoA-I levels were significantly lower in severe, critically ill and mortality groups compared to patients with mild COVID-19 (Wang et al., 2020b; Huang C. et al., 2020; Ouyang et al., 2020; Xie et al., 2020; Zhang Q. et al., 2020; Hilser et al., 2021; Li J. et al., 2021; Turgay Yildırım and Kaya, 2021). This suggests that HDL is associated with COVID-19 severity and risk of death (Tanaka et al., 2020b; Hu et al., 2020; Wang et al., 2020; Wei X. et al., 2020; Zhang B. et al., 2020). During ICU hospitalization in patients with COVID-19, in cases of bacterial superinfection, low HDL concentrations were also found to be correlated with higher mortality (Tanaka et al., 2020c). Significantly, in patients with severe COVID-19, a gradual increase of HDL levels during hospitalization could suggest a path to gradual recovery (Qin et al., 2020a). Moreover, HDL levels influenced the virus shedding duration in patients with COVID19 (Ding et al., 2020) and may predict the risk of hospitalization for COVID-19 (Hamer et al., 2020; Lassale et al., 2021). This data strongly suggests that high HDL levels might be beneficial in patients with COVID-19 through its antiviral activity.

\section{The Possible Mechanism of HDL Action in COVID-19}

Lipid metabolism plays an essential role during SARS-CoV-2 infection. Cholesterol is widely shown to interact with SARSCoV-2 S protein (Kočar et al., 2021). The accumulation of lipids was observed in SARS-CoV-2 infected cells, both in vitro and in the lungs of patients of COVID-19 (Nardacci et al., 2021). In a cell experiment in vitro, HDL showed an obvious antiviral effect on 
TABLE 1 | Changes in HDL levels in patients with COVID-19.

\begin{tabular}{|c|c|c|c|c|}
\hline Author & Country & $\begin{array}{l}\text { Number of } \\
\text { patients }\end{array}$ & Time point & Comparison of HDL levels \\
\hline Wang (Wang et al. (2020a) & China & 228 & $\begin{array}{l}\text { Within } 24 \mathrm{~h} \text { after } \\
\text { admission }\end{array}$ & $\begin{array}{l}\text { COVID-19 patients vs healthy control: median, } 0.78 \text { vs } 1.37 \mathrm{mmol} / \mathrm{L} \text {, } \\
p<0.001 \\
\text { Severe vs non-severe patients: median, } 0.69 \text { vs } 0.79 \mathrm{mmol} / \mathrm{L}, p= \\
0.032\end{array}$ \\
\hline Huang (Huang et al. (2021) & China & 218 & The 1st day of admission & $\begin{array}{l}\text { COVID-19 patients vs healthy control: mean, } 1.02 \mathrm{vs} 1.52 \mathrm{mmol} / \mathrm{L} \text {, } \\
p<0.05 \\
\text { Severe vs non-severe patients: mean, } 0.83 \text { vs } 1.15 \mathrm{mmol} / \mathrm{L}, p<0.05\end{array}$ \\
\hline Zhang (Zhang B. et al. (2020) & China & 74 & Not known & $\begin{array}{l}\text { Severe vs non-severe patients: median, } 0.92 \mathrm{vs} 1.08 \mathrm{mmol} / \mathrm{L}, p= \\
0.021\end{array}$ \\
\hline Xie (Xie et al. (2020) & China & 62 & Not known & $\begin{array}{l}\text { Severe vs non-severe patients with CVD: median, } 1.1 \mathrm{vs} 1.4 \mathrm{mmol} / \mathrm{L} \\
\text { Severe vs non-severe patients without CVD: median, } 1.1 \mathrm{vs} \\
1.3 \mathrm{mmol} / \mathrm{L}\end{array}$ \\
\hline Hu (Hu et al. (2020) & China & 114 & On admission & $\begin{array}{l}\text { COVID-19 patients vs healthy control: mean, } 1.08 \text { vs } 1.27 \mathrm{mmol} / \mathrm{L} \text {, } \\
p<0.001 \\
\text { Severe vs non-severe patients: median, } 1.01 \mathrm{vs} 1.21 \mathrm{mmol} / \mathrm{L}, p< \\
0.001\end{array}$ \\
\hline Wei (Wei et al. (2020b) & China & 597 & Not known & $\begin{array}{l}\text { Mild vs severe vs critical patients: median, } 50 \text { vs } 50 \text { vs } 36 \text { mg/dL, } \\
p<0.05\end{array}$ \\
\hline Tanaka (Tanaka et al. (2020a) & France & 48 & Upon ICU admission & $\begin{array}{l}\text { Alive vs dead patients on day 28: median, } 0.6 \text { vs } 0.5 \mathrm{mmol} / \mathrm{L}, p= \\
0.036\end{array}$ \\
\hline Huang (Huang W. et al. (2020) & China & 2,623 & At admission & $\begin{array}{l}\text { Critical vs non-critical patients: median, } 0.86 \text { vs } 0.95 \mathrm{mmol} / \mathrm{L}, p< \\
0.001\end{array}$ \\
\hline Sun (Sun et al. (2020) & China & 99 & Within $24 \mathrm{~h}$ of admission & Mild vs severe: median, 1.18 vs $0.94, p<0.001$ \\
\hline Ouyang (Ouyang et al. (2020) & China & 107 & Last result & Survivors vs non-survivors: average, 1.07 vs $0.79 \mathrm{mmol} / \mathrm{L}, p=0.006$ \\
\hline Li (Li Y. et al. (2021) & China & 424 & Not known & Survivors vs non-survivors: median, 0.9 vs $0.8, p=0.001$ \\
\hline $\begin{array}{l}\text { Turgay (Turgay Yıldırım and Kaya } \\
\text { (2021) }\end{array}$ & Turkey & 139 & At admission & Survivors vs non-survivors: median, 44.0 vs $28.5 \mathrm{mg} / \mathrm{dL}, p<0.001$ \\
\hline
\end{tabular}

Abbreviations: HDL, high-density lipoprotein; COVID-19, Coronavirus disease 2019.

SARS-CoV-2 via cytopathic effect (CPE) and inhibition activity tests (Cho et al., 2021). Although HDL is believed to play a protective role in infection, some studies have come to the opposite conclusion. Several studies showed HDL facilitated SARS-CoV-2 infection. It was found that HDL significantly increased cell-surface SARS-CoV-2-S binding, viral entry and replication in vitro through SR-B1. Blockade of the cholesterolbinding site on SARS-CoV-2 or treatment with HDL SR-B1 antagonists, inhibits HDL-enhanced SARS-CoV-2 infection (Wei et al., 2020a). Another study showed that pretreatment of 293T cells with an HDL antagonist, in the presence of HDL, strongly inhibited the entry of SARS-CoV-2 into host cells (Wei et al., 2020). It suggested that the down-regulation of HDL levels in patients with COVID-19 may be due to HDL consumption during viral invasion, and HDL or SR-B1 could be treatment targets for COVID-19. However, future studies will need to explore the molecular nature of the interaction between HDL and SARS-CoV-2.

Additionally, clinical data showed influencing the inflammatory response may be one of the mechanisms of HDL involvement in the pathophysiology of COVID-19. Severe COVID-19 is considered to be a sepsis induced by SARS-CoV-2 (Colantuoni et al., 2020; Lin, 2020; Shenoy, 2020), which is characterized by excessive inflammation and multiple-organ failure. It is reported that a marked increase in inflammatory factors occurs in COVID-19, including C-reactive protein (CRP), IL-6, TNF-a, etc. (Song et al., 2020; Zafer et al.,
2021). ApoA-1 and HDL levels were shown to be negatively correlated with CRP and IL-6 levels in patients with COVID-19 (Hu et al., 2020; Sun et al., 2020), suggesting that the increased inflammatory response related to reduced HDL levels is one of the pathogenic mechanisms of COVID-19.

Moreover, apoptosis, oxidative stress and abnormal blood coagulation are all involved in the pathophysiological process of COVID-19 (Tang et al., 2020; Cizmecioglu et al., 2021; Mehri et al., 2021), and multiple studies demonstrated HDL had antithrombotic, anti-apoptotic and anti-oxidative effects (Tanaka et al., 2020a), which offers a possibility that HDL may also regulate these pathways in COVID-19. However, further research is needed to confirm these conclusions.

\section{Therapeutic Strategy of COVID-19 Through Targeting HDL}

Until now effective therapeutic interventions for COVID-19 are limited. Drug repurposing could identify potential treatments in a short time, which has become an important approach to explore therapeutic agents for COVID-19 (Kost-Alimova et al., 2020). As many studies have found that HDL is closely linked to COVID19, some related randomized controlled trial (RCT) studies remain ongoing (Table 2 ). Omega-3 polyunsaturated fatty acids (PUFAs) improve lipid metabolism by reducing triglyceride and increasing HDL (Yanai et al., 2018), which enhance patient's immune function and reduce inflammatory 
TABLE 2 | Clinical studies about drugs that affect HDL on patients with COVID-19.

\begin{tabular}{|c|c|c|c|}
\hline Therapy & ClinicalTrials.gov Identifier & Mechanism of action & Effect on HDL \\
\hline Dalcetrapib & NCT04676867 & CETP inhibitor & Raise HDL levels \\
\hline \multirow[t]{3}{*}{ Omega3-FA } & NCT04658433 & Multifactorial & Raise HDL levels or affect HDL metabolism \\
\hline & NCT04553705 & & \\
\hline & NCT04483271 & & \\
\hline Fenofibrate & NCT04517396 & PPAR-alpha activator & Raise HDL levels \\
\hline \multirow[t]{5}{*}{ Atorvastatin } & NCT04801940 & HMG-CoA reductase inhibitors & Raise HDL levels \\
\hline & NCT04631536 & & \\
\hline & NCT04486508 & & \\
\hline & NCT04466241 & & \\
\hline & NCT04380402 & & \\
\hline \multirow[t]{2}{*}{ Rosuvastatin } & NCT04472611 & HMG-CoA reductase inhibitors & Raise HDL levels \\
\hline & NCT04359095 & & \\
\hline \multirow[t]{2}{*}{ Simvastatin } & NCT04348695 & HMG-CoA reductase inhibitors & Raise HDL levels \\
\hline & NCT04343001 & & \\
\hline
\end{tabular}

Abbreviations: HDL, high-density lipoprotein; COVID-19, Coronavirus disease 2019; HMG-CoA, 3-hydroxy-3-methylglutaryl coenzyme A; CETP, cholesteryl ester transfer protein; PPAR, peroxisome proliferator-activated receptor; FA, fatty acids.

responses (Ni et al., 2020; Sorokin et al., 2020). Subsequently, as it is considered to have a positive role in the treatment of COVID19 , it has become the most studied lipid-regulating drug in COVID-19. Statins, including Atorvastatin, Rosuvastatin, and Simvastatin also showed HDL-increasing capacity (Jones et al., 2003; Miller et al., 2004; Rosenson, 2005; Sasaki et al., 2013), and are one of the current research hotspots of COVID-19. Moreover, RCT studies on the effects of two classic HDL-increasing drugs, CETP inhibitor Dalcetrapib and Fenofibrate, in patients with COVID-19, are also underway. Other HDL-raising pharmacological compounds such as LCAT, have been also considered as potential therapies for COVID-19 (Sorokin et al., 2020).

\section{CONCLUSION}

COVID-19 has spread globally and caused significant morbidity and mortality. Patients with severe COVID-19 are characterized by a dysregulated immune response and abnormal coagulation function, which results in organ dysfunction and ultimately death. HDL possesses several well-documented functions, including regulating immune response, neutralizing endotoxins, anti-oxidation, anti-apoptosis, and anti-thrombosis formation. Multiple studies showed that HDL level, composition and functions were greatly changed in COVID-19 and lower HDL level was correlated with higher risks of severity and mortality, indicating that high HDL levels might be beneficial in COVID-19. HDL level-raising pharmacological compounds

\section{REFERENCES}

Ackermann, M., Verleden, S. E., Kuehnel, M., Haverich, A., Welte, T., Laenger, F., et al. (2020). Pulmonary Vascular Endothelialitis, Thrombosis, and Angiogenesis in Covid-19. N. Engl. J. Med. 383, 120-128. doi:10.1056/ NEJMoa2015432

Albarello, F., Pianura, E., Di Stefano, F., Cristofaro, M., Petrone, A., Marchioni, L., et al. (2020). 2019-novel Coronavirus Severe Adult Respiratory Distress such as CETP inhibitors and fibrates are considered to be potential treatments for patients with COVID-19, and they are already in the preclinical research stage. Until now, there are still relatively few studies on the mechanisms about the protective role of HDL in COVID-19. Notably, many studies related to sepsis support that increasing the levels of HDL in septic patients may be a feasible treatment target. However, simply increasing the level of HDL does not seem to be enough to restore the function of HDL. Therefore, we still need to comprehensively understand the mechanism of HDL action in COVID-19 and improve new strategies for the treatment of patients with COVID-19, by further in-depth study on the composition, structure, and function of HDL in COVID-19.

\section{AUTHOR CONTRIBUTIONS}

Conceptualization, YZ and GW; methodology, YZ; software, JD; validation, YZ; formal analysis, YZ; investigation, JD; resources, JD; data curation, YZ; writing-original draft preparation, GW; writing-review and editing, YZ; supervision, JL, CW, HD, and SW. All authors have read and agreed to the published version of the manuscript.

\section{FUNDING}

This research was funded by Scientific Research Project of Hunan Provincial Health Commission, grant number 202117010786.

Syndrome in Two Cases in Italy: An Uncommon Radiological Presentation. Int. J. Infect. Dis. 93, 192-197. doi:10.1016/j.ijid.2020.02.043

Angelovich, T. A., Hearps, A. C., Oda, M. N., Borja, M. S., Huynh, D., Homann, S., et al. (2017). Dysfunctional High-Density Lipoprotein from HIV+ Individuals Promotes Monocyte-Derived Foam Cell Formation In Vitro. Aids 31, 2331-2336. doi:10.1097/qad.0000000000001642

Aragonès, G., Beltrán-Debón, R., Rull, A., Rodríguez-Sanabria, F., FernándezSender, L., Camps, J., et al. (2010). Human Immunodeficiency Virus-Infection Induces Major Changes in High-Density Lipoprotein Particle Size Distribution 
and Composition: The Effect of Antiretroviral Treatment and Disease Severity. Clin. Chem. Lab. Med. 48, 1147-1152. doi:10.1515/cclm.2010.218

Aung, N., Khanji, M. Y., Munroe, P. B., and Petersen, S. E. (2020). Causal Inference for Genetic Obesity, Cardiometabolic Profile and COVID-19 Susceptibility: A Mendelian Randomization Study. Front. Genet. 11, 586308. doi:10.3389/ fgene. 2020.586308

Baker, J., Ayenew, W., Quick, H., Hullsiek, K. H., Tracy, R., Henry, K., et al. (2010). High-Density Lipoprotein Particles and Markers of Inflammation and Thrombotic Activity in Patients with Untreated HIV Infection. J. Infect. Dis. 201, 285-292. doi:10.1086/649560

Barrientos-Arenas, E., Henao-García, V., Giraldo, D. M., Cardona, M. M., Urcuqui-Inchima, S., Castaño, J. C., et al. (2018). Modulación de los niveles de lipoproteínas de alta densidad y las citoquinas IL- $1 \beta$ e IL- 6 en pacientes con dengue. Rev. Peru Med. Exp. Salud Publica 35, 15-24. doi:10.17843/ rpmesp.2018.351.3568

Begue, F., Tanaka, S., Mouktadi, Z., Rondeau, P., Veeren, B., Diotel, N., et al. (2021). Altered High-Density Lipoprotein Composition and Functions During Severe COVID-19. Sci. Rep. 11, 2291. doi:10.1038/s41598-021-81638-1

Beltrán-García, J., Osca-Verdegal, R., Pallardó, F. V., Ferreres, J., Rodríguez, M., Mulet, S., et al. (2020). Oxidative Stress and Inflammation in COVID-19Associated Sepsis: The Potential Role of Anti-oxidant Therapy in Avoiding Disease Progression. Antioxidants 9, 936. doi:10.3390/antiox9100936

Cai, L., Ji, A., De Beer, F. C., Tannock, L. R., and Van Der Westhuyzen, D. R. (2008). SR-BI Protects against Endotoxemia in Mice through its Roles in Glucocorticoid Production and Hepatic Clearance. J. Clin. Invest. 118, 364-375. doi:10.1172/jci31539

Calabresi, L., Rossoni, G., Gomaraschi, M., Sisto, F., Berti, F., and Franceschini, G. (2003). High-Density Lipoproteins Protect Isolated Rat Hearts From IschemiaReperfusion Injury by Reducing Cardiac Tumor Necrosis Factor- $\alpha$ Content and Enhancing Prostaglandin Release. Circ. Res. 92, 330-337. doi:10.1161/ 01.res.0000054201.60308.1a

Canturk, N., Canturk, Z., Okay, E., Yirmibesoglu, O., and Eraldemir, B. (2002). Risk of Nosocomial Infections and Effects of Total Cholesterol, HDL Cholesterol in Surgical Patients. Clin. Nutr. 21, 431-436. doi:10.1054/ clnu. 2002.0575

Cao, X., Yin, R., Albrecht, H., Fan, D., and Tan, W. (2020). Cholesterol: A New Game Player Accelerating Endothelial Injuries Caused by SARS-CoV-2? Am. J. Physiol. Endocrinol. Metab. 319, E197-e202. doi:10.1152/ajpendo.00255.2020

Chambers, J. P., Yu, J., Valdes, J. J., and Arulanandam, B. P. (2020). SARS-CoV-2, Early Entry Events. J. Pathog. 2020, 1-11. doi:10.1155/2020/9238696

Chien, J.-Y., Jerng, J.-S., Yu, C.-J., and Yang, P.-C. (2005). Low Serum Level of HighDensity Lipoprotein Cholesterol Is a Poor Prognostic Factor for Severe Sepsis*. Crit. Care Med. 33, 1688-1693. doi:10.1097/01.ccm.0000171183.79525.6b

Cho, K.-H., Kim, J.-R., Lee, I.-C., and Kwon, H.-J. (2021). Native High-Density Lipoproteins (HDL) With Higher Paraoxonase Exerts a Potent Antiviral Effect against SARS-CoV-2 (COVID-19), While Glycated HDL Lost the Antiviral Activity. Antioxidants 10, 209. doi:10.3390/antiox10020209

Cirstea, M., Walley, K. R., Russell, J. A., Brunham, L. R., Genga, K. R., and Boyd, J. H. (2017). Decreased High-Density Lipoprotein Cholesterol Level Is an Early Prognostic Marker for Organ Dysfunction and Death in Patients with Suspected Sepsis. J. Crit. Care 38, 289-294. doi:10.1016/j.jcrc.2016.11.041

Cizmecioglu, A., Akay Cizmecioglu, H., Goktepe, M. H., Emsen, A., Korkmaz, C., Esenkaya Tasbent, F., et al. (2021). Apoptosis-induced T-cell Lymphopenia Is Related to COVID-19 Severity. J. Med. Virol. 93, 2867-2874. doi:10.1002/ jmv.26742

Colantuoni, A., Martini, R., Caprari, P., Ballestri, M., Capecchi, P. L., Gnasso, A., et al. (2020). COVID-19 Sepsis and Microcirculation Dysfunction. Front. Physiol. 11, 747. doi:10.3389/fphys.2020.00747

De Nardo, D., Labzin, L. I., Kono, H., Seki, R., Schmidt, S. V., Beyer, M., et al. (2014). High-Density Lipoprotein Mediates Anti-inflammatory Reprogramming of Macrophages Via the Transcriptional Regulator ATF3. Nat. Immunol. 15, 152-160. doi:10.1038/ni.2784

Deguchi, H., Pecheniuk, N. M., Elias, D. J., Averell, P. M., and Griffin, J. H. (2005). High-Density Lipoprotein Deficiency and Dyslipoproteinemia Associated with Venous Thrombosis in Men. Circulation 112, 893-899. doi:10.1161/ circulationaha.104.521344

Delgado-Rodríguez, M., Medina-Cuadros, M., Martínez-Gallego, G., and SilleroArenas, M. (1997). Total Cholesterol, HDL-Cholesterol, and Risk of
Nosocomial Infection: A Prospective Study in Surgical Patients. Infect. Control. Hosp. Epidemiol. 18, 9-18. doi:10.1086/647494

Ding, X., Zhang, J., Liu, L., Yuan, X., Zang, X., Lu, F., et al. (2020). High-density Lipoprotein Cholesterol as a Factor Affecting Virus Clearance in Covid-19 Patients. Respir. Med. 175, 106218. doi:10.1016/j.rmed.2020.106218

Diurno, F., Numis, F. G., Porta, G., Cirillo, F., Maddaluno, S., Ragozzino, A., et al. (2020). Eculizumab Treatment in Patients with COVID-19: Preliminary Results from Real Life ASL Napoli 2 Nord Experience. Eur. Rev. Med. Pharmacol. Sci. 24, 4040-4047. doi:10.26355/eurrev_202004_20875

Ferretti, G., Bacchetti, T., Moroni, C., Vignini, A., and Curatola, G. (2003). Protective Effect of Human HDL against $\mathrm{Cu}(2+)$-Induced Oxidation of Astrocytes. J. Trace Elem. Med. Biol. 17 Suppl 1 (Suppl. 1), 25-30.

Freudenberg, M. A., Bøg-Hansen, T. C., Back, U., and Galanos, C. (1980). Interaction of Lipopolysaccharides with Plasma High-Density Lipoprotein in Rats. Infect. Immun. 28, 373-380. doi:10.1128/iai.28.2.373-380.1980

Ginsberg, H. N. (1998). Lipoprotein Physiology. Endocrinol. Metab. Clin. North America 27, 503-519. doi:10.1016/s0889-8529(05)70023-2

Giunta, R. E., Frank, K., Costa, H., Demirdöver, C., Di Benedetto, G., Elander, A., et al. (2020). The COVID-19 Pandemic and its Impact on Plastic Surgery in Europe - an ESPRAS Survey. Handchir Mikrochir Plast. Chir 52, 221-232. doi:10.1055/a-1169-4443

Gordon, D. J., Probstfield, J. L., Garrison, R. J., Neaton, J. D., Castelli, W. P., Knoke, J. D., et al. (1989). High-density Lipoprotein Cholesterol and Cardiovascular Disease. Four Prospective American Studies. Circulation 79, 8-15. doi:10.1161/01.cir.79.1.8

Griffin, J. H., Kojima, K., Banka, C. L., Curtiss, L. K., and Fernández, J. A. (1999). High-density Lipoprotein Enhancement of Anticoagulant Activities of Plasma Protein S and Activated Protein C. J. Clin. Invest. 103, 219-227. doi:10.1172/ jci5006

Grion, C. M. C., Cardoso, L. T. Q., Perazolo, T. F., Garcia, A. S., Barbosa, D. S., Morimoto, H. K., et al. (2010). Lipoproteins and CETP Levels as Risk Factors for Severe Sepsis in Hospitalized Patients. Eur. J. Clin. Invest. 40, 330-338. doi:10.1111/j.1365-2362.2010.02269.x

Guan, W.-J., Liang, W.-H., Zhao, Y., Liang, H.-R., Chen, Z.-S., Li, Y.-M., et al. (2020a). Comorbidity and its Impact on 1,590 Patients with COVID-19 in China: A Nationwide Analysis. Eur. Respir. J. 55 (5), 20027664. doi:10.1101/ 2020.02.25.20027664

Guan, W.-j., Ni, Z.-y., Hu, Y., Liang, W.-h., Ou, C.-q., He, J.-x., et al. (2020b). Clinical Characteristics of Coronavirus Disease 2019 in China. N. Engl. J. Med. 382, 1708-1720. doi:10.1056/NEJMoa2002032

Guo, L., Song, Z., Li, M., Wu, Q., Wang, D., Feng, H., et al. (2009). Scavenger Receptor BI Protects against Septic Death through its Role in Modulating Inflammatory Response. J. Biol. Chem. 284, 19826-19834. doi:10.1074/ jbc.M109.020933

Guo, L., Ai, J., Zheng, Z., Howatt, D. A., Daugherty, A., Huang, B., et al. (2013). High Density Lipoprotein Protects against Polymicrobe-Induced Sepsis in Mice* J. Biol. Chem. 288, 17947-17953. doi:10.1074/jbc.M112.442699

Hamer, M., Gale, C. R., Kivimäki, M., and Batty, G. D. (2020). Overweight, Obesity, and Risk of Hospitalization for COVID-19: A Community-Based Cohort Study of Adults in the United Kingdom. Proc. Natl. Acad. Sci. USA. 117, 21011-21013. doi:10.1073/pnas.2011086117

Han, Q., Lin, Q., Jin, S., and You, L. (2020). Coronavirus 2019-nCoV: A Brief Perspective from the Front Line. J. Infect. 80, 373-377. doi:10.1016/ j.jinf.2020.02.010

Hilser, J. R., Han, Y., Biswas, S., Gukasyan, J., Cai, Z., Zhu, R., et al. (2021). Association of Serum HDL-Cholesterol and Apolipoprotein A1 Levels with Risk of Severe SARS-CoV-2 Infection. J. lipid Res. 62, 100061. doi:10.1016/ j.jlr.2021.100061

Ho, F. K., Celis-Morales, C. A., Gray, S. R., Katikireddi, S. V., Niedzwiedz, C. L., Hastie, C., et al. (2020). Modifiable and Non-modifiable Risk Factors for COVID-19, and Comparison to Risk Factors for Influenza and Pneumonia: Results from a UK Biobank Prospective Cohort Study. BMJ open 10, e040402. doi:10.1136/bmjopen-2020-040402

Hu, X., Chen, D., Wu, L., He, G., and Ye, W. (2020). Declined Serum High Density Lipoprotein Cholesterol Is Associated with the Severity of COVID-19 Infection. Clinica Chim. Acta 510, 105-110. doi:10.1016/j.cca.2020.07.015

Huang, C., Wang, Y., Li, X., Ren, L., Zhao, J., Hu, Y., et al. (2020). Clinical Features of Patients Infected with 2019 Novel Coronavirus in Wuhan, China. The Lancet 395, 497-506. doi:10.1016/S0140-6736(20)30183-5 
Huang, S., Zhou, C., Yuan, Z., Xiao, H., and Wu, X. (2021). The Clinical Value of High-Density Lipoprotein in the Evaluation of New Coronavirus Pneumonia. Adv. Clin. Exp. Med. 30, 153-156. doi:10.17219/acem/130606

Huang, W., Li, C., Wang, Z., Wang, H., Zhou, N., Jiang, J., et al. (2020). Decreased Serum Albumin Level Indicates Poor Prognosis of COVID-19 Patients: Hepatic Injury Analysis from 2,623 Hospitalized Cases. Sci. China Life Sci. 63, 1678-1687. doi:10.1007/s11427-020-1733-4

Hui, D. S., I Azhar, E., Madani, T. A., Ntoumi, F., Kock, R., Dar, O., et al. (2020). The Continuing 2019-nCoV Epidemic Threat of Novel Coronaviruses to Global Health - the Latest 2019 Novel Coronavirus Outbreak in Wuhan, China. Int. J. Infect. Dis. 91, 264-266. doi:10.1016/j.ijid.2020.01.009

Jamal, M., Bangash, H. I., Habiba, M., Lei, Y., Xie, T., Sun, J., et al. (2021). Immune Dysregulation and System Pathology in COVID-19. Virulence 12, 918-936. doi:10.1080/21505594.2021.1898790

Ji, D., Zhang, M., Qin, E., Zhang, L., Xu, J., Wang, Y., et al. (2021). Letter to the Editor: Obesity, Diabetes, Non-alcoholic Fatty Liver Disease and Metabolic Dysfunction Associated Fatty Liver Disease Are Proinflammatory Hypercoagulable States Associated with Severe Disease and Thrombosis in Covid-19. Metabolism 115, 154437. doi:10.1016/j.metabol.2020.154437

Jia, E.-Z., Zhao, F.-J., Hao, B., Zhu, T.-B., Wang, L.-S., Chen, B., et al. (2009). Helicobacter pylori Infection Is Associated with Decreased Serum Levels of High Density Lipoprotein, but Not with the Severity of Coronary Atherosclerosis. Lipids Health Dis. 8, 59. doi:10.1186/1476-511x-8-59

Jones, P. H., Davidson, M. H., Stein, E. A., Bays, H. E., Mckenney, J. M., Miller, E., et al. (2003). Comparison of the Efficacy and Safety of Rosuvastatin versus Atorvastatin, Simvastatin, and Pravastatin across Doses (STELLAR ${ }^{\star \star}$ STELLAR $=$ Statin Therapies for Elevated Lipid Levels Compared across Doses to Rosuvastatin. Trial). Am. J. Cardiol. 92, 152-160. doi:10.1016/s00029149(03)00530-7

José, R. J., Williams, A., Manuel, A., Brown, J. S., and Chambers, R. C. (2020). Targeting Coagulation Activation in Severe COVID-19 Pneumonia: Lessons from Bacterial Pneumonia and Sepsis. Eur. Respir. Rev. 29, 200240. doi:10.1183/ 16000617.0240-2020

Kawasaki, T., Akanuma, H., and Yamanouchi, T. (2002). Increased Fructose Concentrations in Blood and Urine in Patients with Diabetes. Diabetes Care 25, 353-357. doi:10.2337/diacare.25.2.353

Kerr, R., Stirling, D., and Ludlam, C. A. (2001). Interleukin 6 and Haemostasis. Br. J. Haematol. 115, 3-12. doi:10.1046/j.1365-2141.2001.03061.x

Kočar, E., Režen, T., and Rozman, D. (2021). Cholesterol, Lipoproteins, and COVID-19: Basic Concepts and Clinical Applications. Biochim. Biophys. Acta Mol. Cel Biol Lipids 1866, 158849. doi:10.1016/j.bbalip.2020.158849

Kost-Alimova, M., Sidhom, E.-H., Satyam, A., Chamberlain, B. T., Dvela-Levitt, M., Melanson, M., et al. (2020). A High-Content Screen for Mucin-1-Reducing Compounds Identifies Fostamatinib as a Candidate for Rapid Repurposing for Acute Lung Injury. Cel Rep. Med. 1, 100137. doi:10.1016/j.xcrm.2020.100137

Lassale, C., Hamer, M., Hernáez, Á., Gale, C. R., and Batty, G. D. (2021). Association of Pre-pandemic High-Density Lipoprotein Cholesterol with Risk of COVID-19 Hospitalisation and Death: the UK Biobank Cohort Study. medRxiv. doi:10.1101/2021.01.20.21250152

Levine, D. M., Parker, T. S., Donnelly, T. M., Walsh, A., and Rubin, A. L. (1993). In Vivo protection against Endotoxin by Plasma High Density Lipoprotein. Proc. Natl. Acad. Sci. 90, 12040-12044. doi:10.1073/pnas.90.24.12040

Li, J., Huang, D. Q., Zou, B., Yang, H., Hui, W. Z., Rui, F., et al. (2021). Epidemiology of COVID-19: A Systematic Review and Meta-analysis of Clinical Characteristics, Risk Factors, and Outcomes. J. Med. Virol. 93, 1449-1458. doi:10.1002/jmv.26424

Li, Y., Zhang, Y., Lu, R., Dai, M., Shen, M., Zhang, J., et al. (2021). Lipid Metabolism Changes in Patients with Severe COVID-19. Clinica Chim. Acta 517, 66-73. doi:10.1016/j.cca.2021.02.011

Lin, H.-Y. (2020). The Severe COVID-19: A Sepsis Induced by Viral Infection? and its Immunomodulatory Therapy. Chin. J. Traumatol. 23, 190-195. doi:10.1016/ j.cjtee.2020.06.002

Lu, H., Stratton, C. W., and Tang, Y. W. (2020). Outbreak of Pneumonia of Unknown Etiology in Wuhan, China: The Mystery and the Miracle. J. Med. Virol. 92, 401-402. doi:10.1002/jmv.25678

Lüscher, T. F., Landmesser, U., Von Eckardstein, A., and Fogelman, A. M. (2014). High-Density Lipoprotein. Circ. Res. 114, 171-182. doi:10.1161/ circresaha.114.300935
Madsen, C. M., Varbo, A., Tybjærg-Hansen, A., Frikke-Schmidt, R., and Nordestgaard, B. G. (2018). U-shaped Relationship of HDL and Risk of Infectious Disease: Two Prospective Population-Based Cohort Studies. Eur. Heart J. 39, 1181-1190. doi:10.1093/eurheartj/ehx665

Mahamid, M., Nseir, W., Khoury, T., Mahamid, B., Nubania, A., Sub-Laban, K., et al. (2020). Nonalcoholic Fatty Liver Disease Is Associated with COVID-19 Severity Independently of Metabolic Syndrome. Eur. J. Gastroenterol. Hepatol. doi:10.1097/meg.0000000000001902

Mastaglio, S., Ruggeri, A., Risitano, A. M., Angelillo, P., Yancopoulou, D., Mastellos, D. C., et al. (2020). The First Case of COVID-19 Treated with the Complement C3 Inhibitor AMY-101. Clin. Immunol. 215, 108450. doi:10.1016/j.clim.2020.108450

McDonald, M. C., Dhadly, P., Cockerill, G. W., Cuzzocrea, S., Mota-Filipe, H., Hinds, C. J., et al. (2003). Reconstituted High-Density Lipoprotein Attenuates Organ Injury and Adhesion Molecule Expression in a Rodent Model of Endotoxic Shock. Shock 20, 551-557. doi:10.1097/01.shk.0000097249.97298.a3

Mehri, F., Rahbar, A. H., Ghane, E. T., Souri, B., and Esfahani, M. (2021). The Comparison of Oxidative Markers between Covid-19 Patients and Healthy Subjects. Arch. Med. Res. S0188-4409 (0121), 00126-00120. doi:10.1016/ j.arcmed.2021.06.004

Miller, M., Dobs, A., Yuan, Z., Battisti, W. P., Borisute, H., and Palmisano, J. (2004). Effectiveness of Simvastatin Therapy in Raising HDL-C in Patients with Type 2 Diabetes and Low HDL-C. Curr. Med. Res. Opin. 20, 1087-1094. doi:10.1185/ 030079904125004105

Montero-Chacón, L. B., Padilla-Cuadra, J. I., Chiou, S. H., and Torrealba-Acosta, G. (2020). High-Density Lipoprotein, Mean Platelet Volume, and Uric Acid as Biomarkers for Outcomes in Patients With Sepsis: An Observational Study. J. Intensive Care Med. 35, 636-642. doi:10.1177/0885066618772825

Nardacci, R., Colavita, F., Castilletti, C., Lapa, D., Matusali, G., Meschi, S., et al. (2021). Evidences for Lipid Involvement in SARS-CoV-2 Cytopathogenesis. Cell Death Dis. 12, 263. doi:10.1038/s41419-021-03527-9

Ni, C., Cao, J., Li, D., Wu, W., Cao, L., and Zhu, C. (2020). Parenteral Nutrition Effects of Omega-3 Fatty Acids on C-Reactive Protein, High-Density Lipoprotein, Lymphocyte Characteristics and the Treatment of Critically Ill Patients. Cel Mol Biol. (Noisy-le-grand) 66, 52-56. doi: $10.14715 / \mathrm{cmb} /$ 2020.66.3.8

Nofer, J.-R., Levkau, B., Wolinska, I., Junker, R., Fobker, M., Von Eckardstein, A., et al. (2001). Suppression of Endothelial Cell Apoptosis by High Density Lipoproteins (HDL) and HDL-Associated Lysosphingolipids. J. Biol. Chem. 276, 34480-34485. doi:10.1074/jbc.M103782200

Oslakovic, C., Krisinger, M. J., Andersson, A., Jauhiainen, M., Ehnholm, C., and Dahlbäck, B. (2009). Anionic Phospholipids Lose Their Procoagulant Properties when Incorporated into High Density Lipoproteins. J. Biol. Chem. 284, 5896-5904. doi:10.1074/jbc.M807286200

Oslakovic, C., Jauhiainen, M., Ehnholm, C., and Dahlbäck, B. (2010). The Role of Phospholipid Transfer Protein in Lipoprotein-Mediated Neutralization of the Procoagulant Effect of Anionic Liposomes. J. Thromb. Haemost. : JTH 8, 766-772. doi:10.1111/j.1538-7836.2010.03744.x

Ouyang, S.-M., Zhu, H.-Q., Xie, Y.-N., Zou, Z.-S., Zuo, H.-M., Rao, Y.-W., et al. (2020). Temporal Changes in Laboratory Markers of Survivors and Nonsurvivors of Adult Inpatients with COVID-19. BMC Infect. Dis. 20, 952. doi:10.1186/s12879-020-05678-0

Pajkrt, D., Doran, J. E., Koster, F., Lerch, P. G., Arnet, B., Van Der Poll, T., et al. (1996). Antiinflammatory Effects of Reconstituted High-Density Lipoprotein during Human Endotoxemia. J. Exp. Med. 184, 1601-1608. doi:10.1084/ jem.184.5.1601

Park, K.-H., and Cho, K.-H. (2011). High-density Lipoprotein (HDL) from Elderly and Reconstituted HDL Containing Glycated Apolipoproteins A-I Share Proatherosclerotic and Prosenescent Properties with Increased Cholesterol Influx. Journals Gerontol. Ser. A: Biol. Sci. Med. Sci. 66A, 511-520. doi:10.1093/gerona/glr016

Parker, T. S., Levine, D. M., Chang, J. C., Laxer, J., Coffin, C. C., and Rubin, A. L. (1995). Reconstituted High-Density Lipoprotein Neutralizes Gram-Negative Bacterial Lipopolysaccharides in Human Whole Blood. Infect. Immun. 63, 253-258. doi:10.1128/iai.63.1.253-258.1995

Pirillo, A., Catapano, A. L., and Norata, G. D. (2015). HDL in Infectious Diseases and Sepsis. Handbook Exp. Pharmacol. 224, 483-508. doi:10.1007/978-3-31909665-0_15 
Qin, C., Minghan, H., Ziwen, Z., and Yukun, L. (2020a). Alteration of Lipid Profile and Value of Lipids in the Prediction of the Length of Hospital Stay in COVID-19 Pneumonia Patients. Food Sci. Nutr. 8, 6144-6152. doi: $10.1002 /$ fsn 3.1907

Qin, C., Zhou, L., Hu, Z., Zhang, S., Yang, S., Tao, Y., et al. (2020b). Dysregulation of Immune Response in Patients With Coronavirus 2019 (COVID-19) in Wuhan, China. Clin. Infect. Dis. 71, 762-768. doi:10.1093/cid/ciaa248

Rader, D. J. (2003). Regulation of Reverse Cholesterol Transport and Clinical Implications. Am. J. Cardiol. 92, 42-49. doi:10.1016/s0002-9149(03)00615-5

Robbesyn, F., Garcia, V., Auge, N., Vieira, O., Frisach, M. F., Salvayre, R., et al. (2003). HDL Counterbalance the Proinflammatory Effect of Oxidized LDL by Inhibiting Intracellular Reactive Oxygen Species Rise, Proteasome Activation, and Subsequent NF-kB Activation in Smooth Muscle Cells. FASEB j. 17, 743-745. doi:10.1096/fj.02-0240fje

Rodríguez-Sanz, A., Fuentes, B., Martínez-Sánchez, P., Prefasi, D., MartínezMartínez, M., Correas, E., et al. (2013). High-density Lipoprotein: a Novel Marker for Risk of In-Hospital Infection in Acute Ischemic Stroke Patients? Cerebrovasc. Dis. 35, 291-297. doi:10.1159/000347077

Rose, H., Woolley, I., Hoy, J., Dart, A., Bryant, B., Mijch, A., et al. (2006). HIV Infection and High-Density Lipoprotein: the Effect of the Disease vs the Effect of Treatment. Metabolism 55, 90-95. doi:10.1016/j.metabol.2005.07.012

Rose, H., Hoy, J., Woolley, I., Tchoua, U., Bukrinsky, M., Dart, A., et al. (2008). HIV Infection and High Density Lipoprotein Metabolism. Atherosclerosis 199, 79-86. doi:10.1016/j.atherosclerosis.2007.10.018

Rosenson, R. S. (2005). HDL-C and the Diabetic Patient: Target for Therapeutic Intervention? Diabetes Res. Clin. Pract. 68 (Suppl. 2), S36-S42. doi:10.1016/ j.diabres.2005.03.013

Samanovic, M., Molina-Portela, M. P., Chessler, A.-D. C., Burleigh, B. A., and Raper, J. (2009). Trypanosome Lytic Factor, an Antimicrobial High-Density Lipoprotein, Ameliorates Leishmania Infection. Plos Pathog. 5, e1000276. doi:10.1371/journal.ppat.1000276

Sasaki, J., Otonari, T., Uchida, Y., Ikeda, Y., Biro, S., and Kono, S. (2013). Effects of Pravastatin and Atorvastatin on HDL Cholesterol and Glucose Metabolism in Patients with Dyslipidemia and Glucose Intolerance: the PRAT Study. Jat 20, 368-379. doi:10.5551/jat.13532

Satyam, A., and Tsokos, G. C. (2020). Curb Complement to Cure COVID-19. Clin. Immunol. 221, 108603. doi:10.1016/j.clim.2020.108603

Satyam, A., Tsokos, M. G., Brook, O. R., Hecht, J. L., Moulton, V. R., and Tsokos, G. C. (2021). Activation of Classical and Alternative Complement Pathways in the Pathogenesis of Lung Injury in COVID-19. Clin. Immunol. 226, 108716. doi:10.1016/j.clim.2021.108716

Sharrett, A. R., Ballantyne, C. M., Coady, S. A., Heiss, G., Sorlie, P. D., Catellier, D., et al. (2001). Coronary Heart Disease Prediction From Lipoprotein Cholesterol Levels, Triglycerides, Lipoprotein(a), Apolipoproteins A-I and B, and HDL Density Subfractions. Circulation 104, 1108-1113. doi:10.1161/hc3501.095214

Shenoy, S. (2020). Coronavirus (Covid-19) Sepsis: Revisiting Mitochondrial Dysfunction in Pathogenesis, Aging, Inflammation, and Mortality. Inflamm. Res. 69, 1077-1085. doi:10.1007/s00011-020-01389-z

Shih, D. M., Gu, L., Xia, Y.-R., Navab, M., Li, W.-F., Hama, S., et al. (1998). Mice Lacking Serum Paraoxonase Are Susceptible to Organophosphate Toxicity and Atherosclerosis. Nature 394, 284-287. doi:10.1038/28406

Shor, R., Wainstein, J., Oz, D., Boaz, M., Matas, Z., Fux, A., et al. (2008). Low HDL Levels and the Risk of Death, Sepsis and Malignancy. Clin. Res. Cardiol. 97, 227-233. doi:10.1007/s00392-007-0611-z

Song, C.-Y., Xu, J., He, J.-Q., and Lu, Y.-Q. (2020). Immune Dysfunction Following COVID-19, Especially in Severe Patients. Sci. Rep. 10, 15838. doi:10.1038/ s41598-020-72718-9

Sorokin, A. V., Karathanasis, S. K., Yang, Z. H., Freeman, L., Kotani, K., and Remaley, A. T. (2020). COVID-19-Associated Dyslipidemia: Implications for Mechanism of Impaired Resolution and Novel Therapeutic Approaches. FASEB j. 34, 9843-9853. doi:10.1096/fj.202001451

Suc, I., Escargueil-Blanc, I., Troly, M., Salvayre, R., and Nègre-Salvayre, A. (1997). HDL and ApoA Prevent Cell Death of Endothelial Cells Induced by Oxidized LDL. Atvb 17, 2158-2166. doi:10.1161/01.atv.17.10.2158

Sun, J. T., Chen, Z., Nie, P., Ge, H., Shen, L., Yang, F., et al. (2020). Lipid Profile Features and Their Associations With Disease Severity and Mortality in Patients With COVID-19. Front. Cardiovasc. Med. 7, 584987. doi:10.3389/ fcvm.2020.584987
Suzuki, M., Pritchard, D. K., Becker, L., Hoofnagle, A. N., Tanimura, N., Bammler, T. K., et al. (2010). High-density Lipoprotein Suppresses the Type I Interferon Response, a Family of Potent Antiviral Immunoregulators, in Macrophages Challenged with Lipopolysaccharide. Circulation 122, 1919-1927. doi:10.1161/ circulationaha.110.961193

Tan, M., Liu, Y., Zhou, R., Deng, X., Li, F., Liang, K., et al. (2020). Immunopathological Characteristics of Coronavirus Disease 2019 Cases in Guangzhou, China. Immunology 160, 261-268. doi:10.1111/imm.13223

Tanaka, S., Labreuche, J., Drumez, E., Harrois, A., Hamada, S., Vigué, B., et al. (2017). Low HDL Levels in Sepsis versus Trauma Patients in Intensive Care Unit. Ann. Intensive Care 7, 60. doi:10.1186/s13613-017-0284-3

Tanaka, S., Couret, D., Tran-Dinh, A., Duranteau, J., Montravers, P., Schwendeman, A., et al. (2020a). High-density Lipoproteins during Sepsis: from Bench to Bedside. Crit. Care 24, 134. doi:10.1186/s13054-020-02860-3

Tanaka, S., De Tymowski, C., Assadi, M., Zappella, N., Jean-Baptiste, S., Robert, T., et al. (2020b). Lipoprotein Concentrations Over Time in the Intensive Care Unit COVID-19 Patients: Results from the ApoCOVID Study. PloS one 15, e0239573. doi:10.1371/journal.pone.0239573

Tanaka, S., Genève, C., Zappella, N., Yong-Sang, J., Planesse, C., Louedec, L., et al. (2020c). Reconstituted High-Density Lipoprotein Therapy Improves Survival in Mouse Models of Sepsis. Anesthesiology 132, 825-838. doi:10.1097/ aln.0000000000003155

Tang, N., Li, D., Wang, X., and Sun, Z. (2020). Abnormal Coagulation Parameters Are Associated with Poor Prognosis in Patients with Novel Coronavirus Pneumonia. J. Thromb. Haemost. 18, 844-847. doi:10.1111/jth.14768

Theilmeier, G., Schmidt, C., Herrmann, J., Keul, P., Schäfers, M., Herrgott, I., et al. (2006). High-Density Lipoproteins and Their Constituent, Sphingosine-1Phosphate, Directly Protect the Heart against Ischemia/Reperfusion Injury In Vivo via the S1P 3 Lysophospholipid Receptor. Circulation 114, 1403-1409. doi:10.1161/circulationaha.105.607135

Tijburg, P. N., Ryan, J., Stern, D. M., Wollitzky, B., Rimon, S., Rimon, A., et al. (1991). Activation of the Coagulation Mechanism on Tumor Necrosis FactorStimulated Cultured Endothelial Cells and Their Extracellular Matrix. The Role of Flow and Factor IX/IXa. J. Biol. Chem. 266, 12067-12074. doi:10.1016/s00219258(18)99066-6

Tosheska Trajkovska, K., and Topuzovska, S. (2017). High-density Lipoprotein Metabolism and Reverse Cholesterol Transport: Strategies for Raising HDL Cholesterol. Anatol J. Cardiol. 18, 149-154. doi:10.14744/ AnatolJCardiol.2017.7608

Trinder, M., Genga, K. R., Kong, H. J., Blauw, L. L., Lo, C., Li, X., et al. (2019). Cholesteryl Ester Transfer Protein Influences High-Density Lipoprotein Levels and Survival in Sepsis. Am. J. Respir. Crit. Care Med. 199, 854-862. doi:10.1164/ rccm.201806-1157OC

Trinder, M., Wang, Y., Madsen, C. M., Ponomarev, T., Bohunek, L., Daisely, B. A., et al. (2021). Inhibition of Cholesteryl Ester Transfer Protein Preserves HighDensity Lipoprotein Cholesterol and Improves Survival in Sepsis. Circulation 143, 921-934. doi:10.1161/circulationaha.120.048568

Turgay Yıldırım, Ö., and Kaya, Ş. (2021). The Atherogenic index of Plasma as a Predictor of Mortality in Patients with COVID-19. Heart Lung: J. Crit. Care 50, 329-333. doi:10.1016/j.hrtlng.2021.01.016

Ulevitch, R. J., Johnston, A. R., and Weinstein, D. B. (1979). New Function for High Density Lipoproteins. Their Participation in Intravascular Reactions of Bacterial Lipopolysaccharides. J. Clin. Invest. 64, 1516-1524. doi:10.1172/ jci109610

van Leeuwen, H. J., Heezius, E. C. J. M., Dallinga, G. M., Van Strijp, J. A. G., Verhoef, J., and Van Kessel, K. P. M. (2003). Lipoprotein Metabolism in Patients with Severe Sepsis. Crit. Care Med. 31, 1359-1366. doi:10.1097/ 01.ccm.0000059724.08290.51

Van Lenten, B. J., Wagner, A. C., Nayak, D. P., Hama, S., Navab, M., and Fogelman, A. M. (2001). High-density Lipoprotein Loses its Anti-inflammatory Properties during Acute Influenza a Infection. Circulation 103, 2283-2288. doi:10.1161/ 01.cir.103.18.2283

Van Sickle, W. A., Wilcox, H. G., Malik, K. U., and Nasjletti, A. (1986). High Density Lipoprotein-Induced Cardiac Prostacyclin Synthesis In Vitro: Relationship to Cardiac Arachidonate Mobilization. J. Lipid Res. 27, 517-522.

Viswambharan, H., Ming, X.-F., Zhu, S., Hubsch, A., Lerch, P., Vergères, G., et al. (2004). Reconstituted High-Density Lipoprotein Inhibits Thrombin-Induced Endothelial Tissue Factor Expression through Inhibition of RhoA and 
Stimulation of Phosphatidylinositol 3-kinase but Not Akt/endothelial Nitric Oxide Synthase. Circ. Res. 94, 918-925. doi:10.1161/ 01.res.0000124302.20396.b7

Wang, D., Hu, B., Hu, C., Zhu, F., Liu, X., Zhang, J., et al. (2020a). Clinical Characteristics of 138 Hospitalized Patients With 2019 Novel CoronavirusInfected Pneumonia in Wuhan, China. Jama 323, 1061-1069. doi:10.1001/ jama.2020.1585

Wang, D., Li, R., Wang, J., Jiang, Q., Gao, C., Yang, J., et al. (2020b). Correlation Analysis between Disease Severity and Clinical and Biochemical Characteristics of 143 Cases of COVID-19 in Wuhan, China: a Descriptive Study. BMC Infect. Dis. 20, 519. doi:10.1186/s12879-020-05242-w

Wang, G., Zhang, Q., Zhao, X., Dong, H., Wu, C., Wu, F., et al. (2020). Low HighDensity Lipoprotein Level Is Correlated with the Severity of COVID-19 Patients: an Observational Study. Lipids Health Dis. 19, 204. doi:10.1186/ s12944-020-01382-9

Wei, C., Wan, L., Yan, Q., Wang, X., Zhang, J., Yang, X., et al. (2020a). HDLscavenger Receptor B Type 1 Facilitates SARS-CoV-2 Entry. Nat. Metab. 2, 1391-1400. doi:10.1038/s42255-020-00324-0

Wei, C., Wan, L., Zhang, Y., Fan, C., and Zhong, H. (2020b). Cholesterol Metabolism-Impact for SARS-CoV-2 Infection Prognosis, Entry, and Antiviral Therapies. [Epub ahead of print]. doi:10.1101/2020.04.16.20068528

Wei, X., Zeng, W., Su, J., Wan, H., Yu, X., Cao, X., et al. (2020). Hypolipidemia Is Associated with the Severity of COVID-19. J. Clin. Lipidol. 14, 297-304. doi:10.1016/j.jacl.2020.04.008

WHO(2021a). Coronavirus (COVID-19) Overview. Available at: https://covid19. who.int/ (Accessed June 30, 2021).

WHO(2021b). Coronavirus Disease (COVID-19) Situation Dashboard of China. Available at: https://covid19.who.int/region/wpro/country/cn (Accessed June 30, 2021).

WHO (2021c). Coronavirus Disease (COVID-19) Situation Dashboard of United States of America. Available at: https://covid19.who.int/region/amro/ country/us (Accessed June 30, 2021).

Xie, Y., You, Q., Wu, C., Cao, S., Qu, G., Yan, X., et al. (2020). Impact of Cardiovascular Disease on Clinical Characteristics and Outcomes of Coronavirus Disease 2019 (COVID-19). Circ. J. 84, 1277-1283. doi:10.1253/ circj.CJ-20-0348

Xiong, Y., Liu, Y., Cao, L., Wang, D., Guo, M., Jiang, A., et al. (2020). Transcriptomic Characteristics of Bronchoalveolar Lavage Fluid and Peripheral Blood Mononuclear Cells in COVID-19 Patients. Emerg. Microbes Infect. 9, 761-770. doi:10.1080/22221751.2020.1747363

Xu, Z., Shi, L., Wang, Y., Zhang, J., Huang, L., Zhang, C., et al. (2020). Pathological Findings of COVID-19 Associated with Acute Respiratory Distress Syndrome. Lancet Respir. Med. 8, 420-422. doi:10.1016/s2213-2600(20)30076-x

Yanai, H., Masui, Y., Katsuyama, H., Adachi, H., Kawaguchi, A., Hakoshima, M., et al. (2018). An Improvement of Cardiovascular Risk Factors by Omega-3 Polyunsaturated Fatty Acids. J. Clin. Med. Res. 10, 281-289. doi:10.14740/ jocmr3362w

Yao, X. H., Li, T. Y., He, Z. C., Ping, Y. F., Liu, H. W., Yu, S. C., et al. (2020). [A Pathological Report of Three COVID-19 Cases by Minimal Invasive
Autopsies]. Zhonghua Bing Li Xue Za Zhi 49, 411-417. doi:10.3760/ cma.j.cn112151-20200312-00193

Young, B. E., Ong, S. W. X., Kalimuddin, S., Low, J. G., Tan, S. Y., Loh, J., et al. (2020). Epidemiologic Features and Clinical Course of Patients Infected With SARS-CoV-2 in Singapore. Jama 323, 1488-1494. doi:10.1001/jama.2020.3204

Yuhanna, I. S., Zhu, Y., Cox, B. E., Hahner, L. D., Osborne-Lawrence, S., Lu, P., et al. (2001). High-Density Lipoprotein Binding to Scavenger Receptor-BI Activates Endothelial Nitric Oxide Synthase. Nat. Med. 7, 853-857. doi:10.1038/89986

Zafer, M. M., El-Mahallawy, H. A., and Ashour, H. M. (2021). Severe COVID-19 and Sepsis: Immune Pathogenesis and Laboratory Markers. Microorganisms 9 , 159. doi:10.3390/microorganisms 9010159

Zhang, B., Dong, C., Li, S., Song, X., Wei, W., and Liu, L. (2020). Triglyceride to HighDensity Lipoprotein Cholesterol Ratio Is an Important Determinant of Cardiovascular Risk and Poor Prognosis in Coronavirus Disease-19: A Retrospective Case Series Study. Dmso 13, 3925-3936. doi:10.2147/dmso.s268992

Zhang, D., Guo, R., Lei, L., Liu, H., Wang, Y., Wang, Y., et al. (2021). Frontline Science: COVID-19 Infection Induces Readily Detectable Morphologic and Inflammation-related Phenotypic Changes in Peripheral Blood Monocytes. J. Leukoc. Biol. 109, 13-22. doi:10.1002/jlb.4hi0720-470r

Zhang, Q., Wei, Y., Chen, M., Wan, Q., and Chen, X. (2020). Clinical Analysis of Risk Factors for Severe COVID-19 Patients With Type 2 Diabetes. J. Diabetes Complications 34, 107666. doi:10.1016/j.jdiacomp.2020.107666

Zhang, Y., Yang, H., Li, S., Li, W.-D., Wang, J., and Wang, Y. (2021). Association Analysis Framework of Genetic and Exposure Risks for COVID-19 in MiddleAged and Elderly Adults. Mech. ageing Dev. 194, 111433. doi:10.1016/ j.mad.2021.111433

Zhou, F., Yu, T., Du, R., Fan, G., Liu, Y., Liu, Z., et al. (2020). Clinical Course and Risk Factors for Mortality of Adult Inpatients with COVID-19 in Wuhan, China: A Retrospective Cohort Study. Lancet 395, 1054-1062. doi:10.1016/ s0140-6736(20)30566-3

Zhou, P., Yang, X.-L., Wang, X.-G., Hu, B., Zhang, L., Zhang, W., et al. (2020). A Pneumonia Outbreak Associated with a New Coronavirus of Probable Bat Origin. Nature 579, 270-273. doi:10.1038/s41586-020-2012-7

Zou, G., He, J., Ren, B., Xu, F., Xu, G., and Zhang, W. (2016). The delta HighDensity Lipoprotein Cholesterol Ratio: A Novel Parameter for Gram-Negative Sepsis. Springerplus 5, 1044. doi:10.1186/s40064-016-2685-4

Conflict of Interest: The authors declare that the research was conducted in the absence of any commercial or financial relationships that could be construed as a potential conflict of interest.

Copyright $\odot 2021$ Wang, Deng, $L i, W u$, Dong, Wu and Zhong. This is an open-access article distributed under the terms of the Creative Commons Attribution License (CC $B Y)$. The use, distribution or reproduction in other forums is permitted, provided the original author(s) and the copyright owner(s) are credited and that the original publication in this journal is cited, in accordance with accepted academic practice. No use, distribution or reproduction is permitted which does not comply with these terms. 